Reviewed Article: Teaching and Learning in Clinic

\title{
Private Lives: Confronting the inherent difficulties of reflective writing in clinical legal education.
}

\section{Rachel Spencer}

\section{University of South Australia}

rachel.spencer@unisa.edu.au

\begin{abstract}
The use of reflective writing has long been recognised as an important component of clinical legal education pedagogy. However, current literature about reflective writing exposes a gap about student perceptions of reflective writing.

This article provides an analysis of the results of formal qualitative research that was conducted into student perceptions of reflective writing in the clinical legal education context. The research was designed to investigate whether students perceived any benefit from reflective writing and what difficulties they actually encountered in the process of writing which is particularly different to other forms of academic assessment. The article explores the exact nature of the difficulties experienced by students and suggests an improved pedagogy of reflective writing in the clinical legal education context. The article offers several suggestions and recommendations as to how this might be achieved.
\end{abstract}

Key words: pedagogy; reflective writing pedagogy; clinical legal education; reflection; teaching and learning framework 


\section{PART I: INTRODUCTION AND BACKGROUND}

The use of reflective writing has long been recognised as an important component of clinical legal education pedagogy. This article concludes a trilogy of work based on my research into reflective writing pedagogy. ${ }^{1}$ Readers are referred to the first article for a comprehensive literature review of the pedagogy of reflective learning and reflective writing, and also for a comprehensive overview of the assessment scheme in the course which I teach. ${ }^{2}$ The purpose of this final article in this series is to consider and respond to specific questions that were raised by my earlier research. ${ }^{3}$ In particular, this article examines the various levels of difficulty perceived by law students in relation to reflective writing. Based on the responses of my own students, I have attempted to disclose the factors that law students articulate as difficulties in the reflective writing process. Using these articulated difficulties as a guide, I also provide a framework for assisting students to themselves overcome the obstacles that they see in their way when they are required to produce assessable reflective writing. As in my earlier articles in this trilogy, I have deliberately adopted the technique of writing in the first person as an example of both reflection in action and reflection on action.

\footnotetext{
* Rachel Spencer is the Director of Professional and Clinical Programs in the School of Law at the University of South Australia

${ }^{1}$ See Spencer, R. (2012) 'Holding Up the Mirror: A theoretical and practical analysis of the role of reflection in Clinical Legal Education', 18 International Journal of Clinical Legal Education 179-214 and Spencer 'First they tell us to ignore our emotions, then they tell us to reflect': The development of a reflective writing pedagogy in clinical legal education through an analysis of student perceptions of reflective writing (forthcoming).

${ }^{2}$ Spencer, above, $\mathrm{n} 1$.

${ }^{3}$ Above.
} 
It has been argued that legal writing pedagogy has its roots in the New Rhetoric, which departed from the traditional, formalist approach to writing in the same way as client-centred legal practice developed in favour of the traditional paternalistic approach towards clients. ${ }^{4}$ The two theories developed at about the same time in the 1970s and 1980s. In reflecting upon their work and their reactions to challenges and various experiences within a clinical legal program, law students are able to practise the New Rhetoric idea that writing is 'a process for creating knowledge, not merely a means for communicating $i^{\prime}{ }^{5}$ and that it is '[n]ot until we are forced to reread and rewrite what we have read and what we have written [that] we come to any clear understanding.' ${ }^{6}$ The New Rhetoric view of reading and writing reflectively encompasses the idea that student reflection involves the 'continuing audit of meaning'7 which should occur 'by continuously monitoring their current understanding of what they are reading, writing, researching, or thinking. ' ${ }^{\text {'It }}$ is the very process of writing that exposes weaknesses in reasoning and authority and forces the lawyer to delve even deeper into the problem to find the root causes and their solutions. ${ }^{9}$ For example, drafting pleadings forces the lawyer (or student) to consider the issues, decide what evidence will be needed, and indeed consider if litigation is in fact an appropriate course of action. Writing a letter to a client enables the client's narrative to be

\footnotetext{
${ }^{4}$ Kowalski, T. 'Toward a pedagogy for teaching legal writing in law school clinics,' (2010-2011) 17 Clinical Law Review, 285, 311.

${ }^{5}$ Berger, Linda, (1999) 'Applying New Rhetoric to Legal Discourse: The Ebb and Flow of Reader and Writer, Text and Context' in 49 Journal of Legal Education 156.

${ }^{6}$ Berger, above, n 3, 157.

7 Richards, I.A. (1942) How To Read a Page 204, 217, cited in Berger, above, n2, 169, n94.

${ }^{8}$ Berger, above, n 5, 169, n94.

${ }_{9}^{9}$ Kowalski, above, n 4, 312.
} 
tested, as indeed it must, and succinct advice to be formulated. Committing a commercial agreement to writing focusses the attention of the parties on the detail of their respective rights and obligations. Most clinical placements require students to write what has been termed 'advanced legal writing' ${ }^{10}$ which requires the exercise of a specific set of writing skills.

Like these various forms of 'legal' writing (letters, court documents, agreements, etc.), reflective writing requires the same level of concentration and the same clarity of thought in order to precisely articulate the thoughts and reactions that the student is experiencing. Reflective writing, it has long been argued, assists with ensuring clarity for students as they negotiate their own personal journeys through their legal education, especially in the clinical sector. The reflective journal also provides a vehicle for law students to develop their own voice as writers. McArdle argues that 'the assignment of imaginative, non-traditional writings can be equally useful, if not more so, to students developing proficiency in formal analytical writing...This work can also open up approaches to professional writing that preserve for the writer a sense of individuality.' ${ }^{11}$ In Australia, out of a total of 26 Clinical Legal Education programs currently operated by law schools, 17 of them (65\%) require students to

\footnotetext{
${ }^{10}$ Kowalski, above, n 4, 285.

${ }^{11}$ Andrea McArdle, 'Teaching Writing in Clinical, Lawyering, and Legal Writing Courses: Negotiating Professional and Personal Voice', (2005-2006) 12 Clinical Law Review 501, 522.
} 
prepare some sort of reflective report or journal as part of the assessment for the applicable course. ${ }^{12}$

Students engaged in clinical legal education programs 'spend a great deal of time planning to write, writing, talking about writing, and then writing some more.'13 However, most of the writing that is discussed between a student and the Clinic supervisor is 'professional' or 'legal' writing. Legal writing pedagogy is different from reflective writing pedagogy. Reflective writing in the clinical context is therefore somewhat paradoxical. It is to be expected that the requirement to produce two very different kinds of writing within the one course could be confusing for students. However, there are a number of elements that are required for good writing of any kind. Grammatical correctness, syntax, sentence construction, spelling, appropriately organised paragraphs and the idea of a beginning, a middle and an end are arguably good basic building blocks for any kind of writing in any discipline. ${ }^{14}$

As explained in an earlier article about this particular project, ${ }^{15}$ my research started from the premise that there appear to be three key assumptions inherent in the expectation of clinical legal educators that students will write an assessable reflective analysis of their clinical placement. The first assumption is that students know how

\footnotetext{
${ }^{12}$ Australian Learning and Teaching Council, 2011, Identifying Current Practices in Clinical Legal Education, San Francisco: Creative Commons.

${ }^{13}$ Kowalski, above, n 4, 286.

${ }^{14}$ For a detailed exploration of the pedagogy of legal writing, see Kowalski, above.

${ }^{15}$ Spencer, this article has also been submitted for review; not yet published.
} 
to reflect and that reflection is a natural innate skill. In a previous article ${ }^{16} \mathrm{I}$ have expressed the view that students need to be taught how to reflect, and clinical teachers must teach the skills of reflection before students are able to reflect effectively. ${ }^{17}$ On the understanding, therefore, that students need guidance on how to reflect, I wanted to ascertain student attitudes towards reflective writing. Email exchanges, corridor discussions and informal class feedback had informed me that some students find reflective writing to be difficult. Conversely, informal feedback had also informed me that some students find reflective writing to be easy, even pleasurable. My formal research aimed to investigate the source of the difficulties that are experienced by those students who are troubled by reflective writing, so that it might be addressed in the future and accordingly inform an enhanced pedagogy.

\section{PART II: APPROACH AND METHODOLOGY.}

The research design envisaged that all students enrolled in my Clinical Legal Education elective course would be asked to respond to a survey about reflective writing. I conducted qualitative research by way of a personal questionnaire. Approval from the relevant University Ethics Committee ${ }^{18}$ was sought and obtained to distribute questionnaires to students enrolled in my Legal Professional and Community Service Experience course. This is a clinical legal education course where

\footnotetext{
16 Spencer, above $\mathrm{n} 1$.

17 See Spencer, n 1, especially pages 187-203.

${ }^{18}$ Human Research Ethics Committee at the University of South Australia.
} 
students are placed at a variety of external placement offices or within the School of Law's own Legal Advice Clinic.

My law school operates on a trimester system, in which the academic year is divided into three terms. The clinical legal education course is offered as an elective course each term. I am the course-co-ordinator and I teach the course for two out of three terms every year. However, in 2013, I did not teach or co-ordinate the course in Terms 1 and 2, and a different member of staff performed this role. A questionnaire was handed out to all students present in the last class at the end of each term for four consecutive terms (Terms 1, 2 and 3 in 2012 and term 1 of 2013), including those classes whom I had not personally taught. Students were provided with an information sheet (see Appendix 1) about the research that was being conducted and invited to participate by writing answers to the questions on the Student Questionnaire (opposite page). Not all students enrolled in the course were present during the time of the questionnaires being handed out, so the responses are not representative of the entire student cohort from each term. However, all students present each time filled out the questionnaires. It was made very clear that it was a voluntary activity. None of the students who were present at the time of the distribution of the questionnaires declined to complete the questionnaire. 
Across the period of four terms, there were a total of 51 students enrolled in the course. ${ }^{19}$ Out of 51 students, 28 students completed the questionnaire, representing $54.9 \%$ of the enrolled students across that period of time. The answers to the questionnaire were handwritten and then submitted to me. All responses were anonymous.

The questions were:

1. Have you found keeping a reflective portfolio to be a positive or negative experience? Why?

2. Do you find reflective writing easy or difficult? Explain.

3. Have you found writing a reflective journal to be a useful exercise? Why or why not?

4. Has the process of being forced to reflect made you more reflective now about other tasks/ work/aspects of your life?

5. Has the process of reflection enhanced or detracted from your placement experience? Please explain your answer.

6. Have you been worried / frustrated / concerned about reflective writing? Please elaborate.

7. Please provide any other feedback you have about the reflective writing component of this course.

The responses to the questions were analysed collectively and no data was recorded in relation to differentiation between different cohorts of students. No changes were made to the course or to the assessment across the four terms from which students

\footnotetext{
${ }^{19}$ A total of 8 students in Term 1 2012; 17 students in Term 2 2012; 9 students in Term 3 2012; 17 students in Term 12013.
} 
were asked to respond to the surveys, so they were all responding after having completed the same course with identical content and assessment. The only difference between different cohorts was that two were taught by a colleague; I taught the other two. It is also possible that differences in placement supervision might have impacted on students' perceptions of reflection. I did not ask students this question and so this issue is not addressed here. However, it is an issue that might merit future exploration.

After completing the questionnaires, students were also invited to attend a focus group to speak in more detail about their experiences of reflective writing. Nine students participated in a focus group ${ }^{20}$ which I facilitated. The focus group was a semi-structured informal meeting of students who responded to the invitation to attend. They were initially asked to 'tell me what you think about reflective writing' and the conversation flowed organically. The comments obtained from the focus group provided some additional insights into students' attitudes towards reflective writing. The aim of the focus group was to obtain more details from students about their attitudes to reflective writing that they might not have written on the survey response sheets.

The focus group discussion was recorded on a digital audio-recorder (with the permission of all participants) and the results transcribed. Students participating in the focus group were provided with a copy of the Participants' Information Sheet

${ }^{20}$ On 4 April 2013. 
(see Appendix 1) and they also signed a Consent Form (see Appendix 2) acknowledging that they were participating voluntarily. Approval was obtained from the University Human Research Ethics Committee to conduct the focus group.

Although some quantitative analysis has been conducted in relation to the responses, the research was predominantly a qualitative study of student responses to the seven questions.

This article provides an analysis of the responses to questions 2, 5 and 6. An analysis of the responses to questions 1, 3 and 4 has been presented in another article. Answers to question 7 of the Questionnaire have been discussed where relevant in both this article and in the companion article. ${ }^{21}$

\section{PART III: RESULTS OF THE RESEARCH \& CONCLUSIONS.}

This part sets out a detailed analysis of the responses to the survey questions 2,5 and 6 and also of some data obtained from the focus group. An analysis of the responses to each question are provided sequentially.

\section{III (i): Do students find reflective writing easy or difficult?}

The responses to Question 2 of the Student Questionnaire provided a helpful insight into student perceptions of the writing process. $50 \%$ of students specifically articulated that they found reflective writing difficult. A further $17 \%$ used words

${ }^{21}$ Spencer, above, $\mathrm{n} 15$. 
expressing levels of difficulty with some but not all aspects of reflective writing. For example:

I find it relatively easy... what I found difficult was putting my experiences into a broader, societal context.

It is easy to write initially about my experiences but reflecting on it later can be different... and... trickier.

Descriptors like 'intensive', 'overwhelmed' and 'difficult' were used, but the students provided thoughtful analyses of why they found the task of reflective writing difficult. This will be particularly useful when addressing future students. For example, one student explained that the difficulty lay in the uncertainty of the subject matter and that it was hard to relate the reflective writing to the journal articles that they were required to read. This indicates a need for greater certainty and specificity in the instructions.

In my experience, the knee-jerk reaction of many students to the idea of reflective writing is hostility. The hostility is often based on a lack of understanding of what is required. For example, one student wrote:

At first I found it extremely difficult and was very overwhelmed by the thought of it.

One difficulty was described as 'putting my experiences into a broader, societal context' - which was an acknowledgement of this as part of critical reflection. This 
same student said that the identification of 'feelings and the actions relating to them' was easy.

These are useful insights which can be incorporated into the wording of instructions to students. In addition, it is important to stress that reflective writing is a good exercise in being articulate and using precise language. These are skills necessary in all types of writing, especially legal writing. Students may appreciate the writing process more if they are aware that the skills they are developing are relevant to 'hard' skills (letters of advice, drafting pleadings, documenting agreements) as well as 'soft' skills (emotional intelligence, empathy, communication skills).

Responses to Question 2 identify the specific actions that students find difficult:

- $\quad$ Tendency to over analyse

- Uncertainty of direction

- $\quad$ Deep thinking

- Presentation of reflection in an understandable way

- Being concise

- Standing in the shoes of other stakeholders

- Making assumptions about others

- $\quad$ Talking about things with others

- Writing thoughts down to share

- Putting experiences into a broader societal context

- Continuity
- $\quad$ Avoidance of 'waffling'

- $\quad$ Expressing feelings

- $\quad$ Thinking deeply

- $\quad$ Keeping a good record of events

- $\quad$ Looking at the placement from different points of view

- $\quad$ Being critical

- $\quad$ Finding motivation

- Critiquing work progress and feelings

- Evaluation of self 
In identifying the difficulties encountered in reflective writing, the students articulated the heart of what makes good reflective writing. So although they have acknowledged that the task was difficult, they have articulated the very attributes that they know are the ingredients of what is required. This reinforces that students need to be taught how to reflect and how to write reflectively. But once they are taught what is required, students embrace the requirements and appear to be intellectually stimulated by the difficulties that the requirements present. The list of difficulties identified above could be presented to students as part of their instructions. This idea is developed in Part IV.

Several students commented on the difficulties of dialogic reflection. These difficulties were:

- deep thinking

- the ability to present personal reflections that can be understood by others

- empathising with other stakeholders

- making assumptions about people

- sharing reflections with others.

- critical reflection

One student summarised the difficulties thus:

It is easy to write initially about my experiences but reflecting on it later can be different. It requires looking at my placement from different points of views and quite critically, which can be trickier. 
Another view appreciated the value of improving analytical skills through reflective writing:

It has not been an easy task. Reflective writing has tested my analytical skills, to think about issues arising from my placement that I would not otherwise have contemplated.

This observation can be used as basis for discussion about what dialogic reflection involves. Again, the identification of these difficulties confirms that students know what is required of them and indicates that while finding the task difficult or uncomfortable, students are conscious of the issues they need to address.

A number of the comments identify difficulties that are relevant to all kinds of writing, not just reflective writing: how to get over writer's block and how to edit rigorously. These are not difficulties reserved for reflective writing. As with all writing, regular practice is the key. One student identified experiencing:

... occasions where the ink just flows $\mathcal{E}$ thoughts are able to spill onto the paper as an extension of the brain. At other times I think I can tend to over analyse $\mathcal{E}$ mull over situations too much creating the scenario where you don't know in which direction to head. In saying that, a lot of times you start in one direction $\mathcal{E}$ by the time your finish (sic) - end up in an entirely different position than one would have thought.

The above observation summarises the struggle that many students face. However, ending up in a different position to the originally anticipated position is not necessarily a problem. The shifting of perspective is part of the 'disorienting 
moment'. ${ }^{22}$ One goal of reflection is to venture down paths hitherto unwalked. For the student who might be unused to trying new ways of thinking, reflection is the perfect opportunity to end up in a different position, and be intellectually enlightened because of it.

A few commented on the 'artificiality' of reflective writing. Writing initially about their experiences was generally expressed to be easy, but the critical analysis of their experiences, especially from different points of view was seen to be one of the most challenging aspects of reflective writing. A number of students acknowledged the requirement to write more than, for example, 'just a basic review of what we've done each day at the placement'.

An area which was repeatedly described by students as an area of difficulty was the discomfort experienced in writing about the self. Students were very articulate about this. One student described this as 'navel gazing' in 'self-indulgent proportions'. A number of students said that they reflected 'in my own head' but found expressing their feelings in writing to be difficult. Another said:

I find reflective writing quite challenging as I feel quite awkward and uncomfortable critiquing my own work progress and feelings. The actual writing poses no difficulty, but the evaluation of my self is hard. It isn't something I enjoy, but I completely understand its relevance to me and my future.

\footnotetext{
${ }^{22}$ Quigley, F. (1995) 'Seizing the Disorienting Moment', 2 Clinical Law Review 37, 51, cited in Aiken J.H. (1997) 'Striving to Teach Justice, Fairness and Morality', 4 (1) Clinical Law Review 1, 24 and 25.
} 
One student was particularly strident about being forced to disclose private feelings:

Very difficult. Reflective (sic) is something that I do every day. I dislike writing my personal reflections and disclosing it to somebody else. It's something I value privately.

One issue of concern that was discussed in the Focus Group was the fact that some students felt that their training to be objective in their academic writing was so entrenched that it hindered their ability to talk about themselves and their subjective reactions to their placements and the topics covered in classes. When required to engage in deep personal reflection, students found this confronting and confusing because it was the complete opposite to what they had previously been taught. The students also pointed out that they had been taught by all their other lecturers not to become emotionally involved with their work and that they must remain professionally detached from their clients. Yet in my course they are required to reflect and develop emotional intelligence and write about their personal reactions. Students found it completely disorienting that their training in emotional detachment was being challenged.

One student was very passionate about this, and voiced concerns in an urgent, almost desperate tone that would have been difficult to convey in a written response to a questionnaire. It was useful to hear this view in the Focus Group. The student said: 
... we are made to look at everything so ... objectively and we are meant to like blank ourselves out from having any emotional connection to anything in the sense that you can't get too attached to something otherwise it will drive you insane and then we have to do all this emotional reflection on stuff and then my brain is virtually, like, 'Stop emotionally reflecting on anything!' So then you are just basically writing about how you feel about stuff and I'm like, 'How the hell am I supposed to do that?' It's just very different from everything that we've been taught how to do. Which is obviously a good thing but at the same time it's like, a pretty difficult thing to do.

This urgent plea encapsulates the overarching student difficulty with reflective writing and simultaneously highlights a major problem with modern legal education. Other students in the Focus Group agreed that the subjective nature of reflective writing was contrary to the approach that they had so far been taught. One student said that they had all been taught to 'turn to stone' and to ignore any emotional connection with their subject matter when dealing with legal issues. The concept of professional detachment was considered to be so completely anathema to the idea of reflection that it left them feeling very confused. This raises the issue of different teaching philosophies and the approach to clients amongst academic staff within the same school.

There is a conflict between those law teachers who advocate maintaining professional distance by disallowing the self from becoming 'emotionally involved' and those law teachers who profess that the development of emotional intelligence 
and empathy are critical not only for efficient and successful legal practice but also for the preservation of mental health and a sense of fulfilment in one's work as a legal practitioner. For law students, this is creating confusion. For clinical teachers, the challenge is to guide students through these apparently conflicting principles. The scope of this paper does not allow for a detailed examination of this important dilemma, but it is clearly an important factor to be considered when teaching students about the value of reflection.

Other students provided important feedback about reflective writing as an assessable component of the course. Two students were of the view that reflective writing should not be 'such a big part of the assessment'. Others appreciated the opportunity to improve their writing as the term progressed. For example:

It's been a welcomed change doing reflective writing for more than 1 assessment for the same subject. I feel as though I have learnt more on reflective writing than in the past because I get a chance to read the criticism and then try and improve the next assessment.

Other students comment less favourably about assessable reflective writing:

Perhaps only make one of the assessment pieces based on reflection. At the moment all $\underline{3}$ pieces of work require "deep reflection". I don't feel as though I am learning...

It would be nice if it wasn't such a big part of the assessment of the course. 
Some students took advantage of the opportunity afforded to all students (but not necessarily taken up by all students) to submit weekly journal drafts to me for feedback. Those who did this produced noticeably better final pieces of reflective writing for their final assessment. After gathering data for this article, I have implemented a slightly different assessment scheme which requires all students to submit four short journal entries (200 words) across the term. I then provide feedback on those pieces, which the students are at liberty to develop into their final reflective portfolio at the end of the term. Each of these short journal entries is worth $5 \%$ of their overall portfolio mark. Already this has proved successful with students producing better work each time. I have also noticed a considerable increase in both quality and quantity of class discussions since implementing the mandatory journal entry requirement.

The pedagogical message from the responses to Question 2 is that students require ongoing guidance and encouragement in relation to their reflective writing. Guidance and assistance in relation to critical analysis is important to assist students with the development and improvement of their reflective writing. Constructive feedback is vital for students whose writing lacks critical insight. For example, comments from supervisors or course co-ordinators like 'go deeper' or 'needs more critical analysis' are not enough. This was highlighted in the Focus Group. The marker must identify examples of where and how the student can delve more critically into their own experiences by asking specific questions like: 
- What aspects of your own background do you think make you feel like this?

- You seem to feel very strongly about this? What aspects of your personality are relevant to this?

- Do your own values have a bearing on this? What are the values that are important to you in this context?

- Why do you think the client might have said that?

- What exactly made you feel frustrated?

- How might you do this differently next time?

- What made this such a good day?

- Why do you think this make you angry? Why did it matter to you?

- Are there any articles that cover this subject?

- Do you agree with what (author of article on reading list) says about clients in this situation?

III (ii): Has the process of reflection enhanced or detracted from the student placement experience?

18 out of 29 students said that the process of reflection had enhanced their placement experience. Six said that it had detracted from the experience. Two said that it had neither enhanced nor detracted from the placement experience.

Many of those students who said that that the process of reflection has enhanced the experience, focussed on their own learning and personal progress. Students commented favourably on thinking back on all the particulars of day to day work / client interviews etc. and writing them down'; many emphasised the ability to 'reflect on my 
progress', look back at my past experiences and learning from them. For example, one student remarked that on the occasion of dealing with a 'difficult client', writing about that experience enabled that student to 'look back on how I first dealt with the experience' and then to 'modify... my reactions positively'.

Those who found that the reflection enhanced their Placement experience said that this was because it helped them to organise what they had learned:

Otherwise so much happens in a day that I might just forget what's happened $\mathcal{E}$ fail to realise what I've learnt $\mathcal{E}$ what progress has been made.

One student said that reflective writing had helped to distil exactly what was being learned from the experience and that it was also helping to shape and direct what that student wanted from the placement experience. This relates directly to the class time that we spend on goal setting and planning for the placement. As part of their placement preparation I always advise students about the unpredictability of workplace environments and that they should 'expect the unexpected' while they are on placement. One student directly commented on this:

It made me aware to aspect (sic) the unexpected and ... think... twice over anything and not to ignore any incident no matter how small or bigger that incident might be.

One said that the writing process slightly detracted from the placement experience but: 
... only because of where I am for my placement. I really do not deal with most of the topics we have talked about so have found it really difficult to try \& relate the topics back to my placement \& talk about them.

This is an important observation which has illuminated the necessity of ensuring that all classes are relevant to all placements. Even if most students in the class are placed in one particular location (e.g. the Legal Advice Clinic) it is important to constantly bring the awareness of all students back to the fact that there are a variety of placement environments. This is a deliberate pedagogical strategy for enabling discussion about the variety of work for lawyers and the different approaches to legal practice and the use of legal skills and training.

The clinical teacher must be mindful that students may not all be placed in the same organisation or they may have different experiences within an organisation. I endeavour to be inclusive in all classes, but this feedback indicates that one must always be mindful of this.

Those who found the reflective writing process to detract from the placement experience had various reasons for this:

Detracted as it means that there is always something else that is in the back of my mind, i.e. that I need to be constantly reflecting on my actions and work, as often there is nothing to really reflect on, as the work is straightforward. Therefore, sometimes I need to create something so that I know that I will have something that I can write about, and hence can't fully concentrate on the work that I have been given. 
This observation above is interesting. There are two alternate explanations. Either this student found that the requirement to reflect intruded into the actual placement tasks which were 'straightforward', or the student was not challenged by the placement tasks and therefore could have reflected on why not, and how to seek out more challenging opportunities. This appears to be an indication that the student was actually naturally engaged in 'reflection-in-action'.

Five students noted that reflective writing detracted from the placement experience because they were worried about what they were going to write about and that having to write about their placement experiences detracted from the enjoyment of it. There was a feeling amongst some students that the writing became repetitive.

It helped / enhanced for the first few weeks of the course when everything was new. Now, I find it repetitive and boring. I feel like I'm repeating the same words throughout all 3 assessment pieces. ${ }^{23}$

This highlights the need for me to emphasise the need for students to reflect on their progress and their goals. On the other hand, the final portfolio submission requires students to submit answers to specific questions (see Appendix 4) so the possibility of repetition is eliminated.

Some students were pragmatic in their responses, finding that reflection enhanced the experience because of the direct link to assessment. Some appreciated the

\footnotetext{
${ }^{23}$ This student wrote this same wording twice, for 2 separate questions. The three assessment pieces are actually very different. One is a Critical Incident Report, one is a seminar presentation on an article from the reading list and the third is a reflective portfolio (which cannot include the incident used for assignment 1 ).
} 
opportunity to use the journal writing as a first draft of their final portfolio submission (which was encouraged at the time of this research being conducted and is now mandatory), or because the requirement to write a journal entry provided a task when the placement did not:

It has enhanced my experience but that may have been because it gave me something to do - there was a lot of just sitting and listening for long periods of time in my placement, which could sometimes be dull. Writing and reflecting on what was occurring filled up my time.

Some students liked the focus on the emotional aspects of the placement. One student articulated the necessity to:

... really focus on my feelings whilst being there, thus being more alert, and willing to perform more tasks.

Another said that written reflections enabled an acknowledgement of:

... what I'm worried about and realise what challenges may be for me.

One said:

I think it has kept it grounded for me. It puts things into perspective for me.

Focussing on feelings was said by many to have assisted self-awareness, for example:

Definitely enhanced my placement experience. I enjoyed reflecting and becoming aware of my strengths and weaknesses and how I could 
improve. Self-awareness is the first step to change therefore reflection is a very effective tool.

One student found that it directly facilitated empathy. This student said that reflection enhanced the ability to analyse and understand the behaviour of others. This in turn enhanced the student's interviewing skills:

I am now able to read a client's expressions and respond appropriately.

Others emphasised the positive aspects of monitoring their progress. A recurring comment was that students liked to be able to look back on experiences and learn from them.

I enjoyed reflecting and becoming aware of my strengths and weaknesses and how I could improve. Self-awareness is the first step to change therefore reflection is a very effective tool.

The positive comments which assert that reflective writing enhances the placement reinforce the literature which advocates reflective writing as a key component of clinical legal education. Other comments suggest that 'prompts' need to be included as part of the instructions for reflective writing assessment exercise. They also underscore the need to ensure that assignment instructions are clear.

III (iii): Are students worried / frustrated / concerned about reflective writing?

The responses to Question 6 of the Student Questionnaire fell into three main categories: those students who felt worried, frustrated or concerned because they felt 
uncertain whether their writing would achieve the desired grade, those who were uncertain about appropriate subject matter for reflection, and those who stated that they had not been worried, frustrated or concerned.

$28 \%$ of students were very confident and expressed no concern or anxiety. They felt in control and were not worried at all by reflective writing:

No as I feel it's a task that is very much in my control.

I was never worried about reflective writing. I know it is a beneficial tool - helping in learning, using past experiences to perfect future ones.

Five students repeated the word 'frustrated'. They were frustrated because they felt they had nothing to write about, or they could not relate to what everyone else was saying in class discussions, or because they did not want to disclose their personal reflections to anyone else:

Frustrated!! ... how can someone question your reflection when it is your experience and not theirs?

I am frustrated and concerned about it. Frustrated because I dislike disclosing my personal reflections / issues to somebody else. At the same time, writing something artificial because I value my privacy makes me concerned that my artificiality is reflected in my writing.

Although the term frustration is expressed by only five students, this represents almost one fifth of the surveyed students so it is a concern worth noting. If these comments were raised in reflective writing, I would be asking the student (s) to 
reflect critically on why they are feeling this way. For example, I would ask them to address questions such as: What is it about your personality that you think makes you feel this way - do you like to be in control? Have you been bored? What does this tell you about the type of place you would like to work? ${ }^{24}$

A number of students repeated the word 'worried'. This was in the context of concern about lack of subject matter, and therefore a potentially low grade. For example:

Slightly worried, only in a sense that I have not reflected enough in certain situations etc.

I have been worried I won't have enough content from placement to fulfil the requirements of the portfolio

In terms of an assessment I have been worried that I cannot improve my writing style effectively enough to improve my marks.

I am only really worried that the experiences I have had do not fit neatly into the pre-ordained reflective categories for the reflective portfolio.

I realise that I am not very good at it, so therefore it has been harder to get to the required standard.

Only one student was worried about disclosing reflections about emotions:

${ }^{24}$ See Spencer, above, $\mathrm{n} 1$ for a variety of suggestions for stimulating reflective writing. 
Only thing I am worried about is telling you.... I don't talk about my emotions to anyone.

Even though only one student voiced a concern about privacy, it is important to consider this complex issue. Students should not be expected to divulge sentiments that they do not wish to disclose to anyone. The trust between clinical teacher and student is of critical importance and can take a long time to establish. Some students will readily write about their personal thoughts and how they react to different situations. Others may be much more private about their feelings. Others may have complex backgrounds that they are not comfortable sharing. Clinical teachers must always be aware that in any class, it is quite probable that there will be students who live with a wide range of difficulties, such as mental illness, abusive partners, backgrounds of sadness, anguish or torment which have shaped their personalities and their attitudes. Not all students will be prepared or able to write about or discuss this. Clinical teachers must make it clear to students that they are not expected to disclose anything unless they feel comfortable doing so. On the other hand, teachers must give guidance to all students to be mindful of how past experiences have shaped who they are today. The response about 'not talking about my emotions to anyone' is a reminder of the privileged position that the clinical teacher occupies. To be privy to students' private reflections about their hopes and dreams and their personal recognition of the backgrounds that have shaped their personalities is indeed a rare and special one. It is critical that clinical educators respect this privilege. 
The dominant theme raised as a concern was the assessment of reflective writing. Several comments suggest that while some students were not anxious about the reflective writing task itself, they did have concerns about whether they had reflected "enough", or "deep enough" or "to the level of detail needed", for example:

I am often worried about reflective writing because I find markers can always find something you could have elaborated on more etc. I find it very difficult to achieve an HD standard in reflection exercises.

Others were concerned about the way that their writing was assessed. One student said:

marking someone's ability to reflect seems pointless.

Some questioned the validity of marking a subjective reflection. However, this highlights the need to explain the necessity of dialogic reflection, which takes the student beyond a consideration of merely their own personal reactions to events and situations. For example:

How I understand a situation and record these facts may not necessarily be the same as the lecturer. Can be subjective...

This student's comment is at the heart of critical reflection writing. Students are required to analyse and reflect from multiple perspectives. This has alerted me to the need to discuss this area of concern in classes, and to reinforce the requirement for dialogic reflection. These concerns demonstrate a need for clear guidance to be given to students about the exact requirements of the assessment tasks and how to achieve 
a high grade. They also reinforce the arguments put forward by me that students do not innately know how to reflect and how to write reflectively and must be taught. ${ }^{25}$

Student responses that indicated a high level of perceived improvement in reflective writing were an encouraging suggestion that my pedagogy of progressively developing trust within the class ${ }^{26}$ is effective as a means of teaching the skill of reflective writing. For example:

Before this course and evidence course (where I also had to reflect) I did not like reflective writing because I never really had direction about how to write a good reflection but after reading Jenny Moon's articles $^{27}$ and learning from Rachel, I feel much more at ease about reflective writing.

At first it took a little to warm up to the activity but it has become easier.

It is of concern that the reflective writing tasks within the clinical legal education course causes students to worry, and steps must be taken to alleviate this type of anxiety in the future. It would appear that reflective writing pedagogy must include appropriate recognition of student concerns and appropriate steps to resolve those concerns. This is addressed in Part IV (Recommendation 8).

\footnotetext{
${ }^{25}$ Spencer, above, $\mathrm{n} 1$.

${ }^{26}$ Spencer, above, n 1, p 196.

${ }^{27}$ The author includes several chapters from the following text as reading materials for students: Jennifer Moon (2004), A Handbook of Reflective and Experiential Learning: Theory and Practice, Routledge Falmer.
} 


\section{PART IV: CONCLUSIONS AND RECOMMENDATIONS}

The research unearthed a variety of issues to be addressed in order to enhance reflective writing pedagogy. Where concerns and anxieties have been raised it is hoped that these can be reduced or eliminated. Some of the students' responses raised issues that I had not previously considered. This has informed my teaching practice and has added to the scholarship of teaching and learning in this area.

\section{Dealing with negativity}

Part II outlined some of the negative reactions that some students described when confronted with the task of reflective writing, such as feeling 'quite awkward and uncomfortable' and 'overwhelmed'. While these feelings are a necessary part of the clinical experience because they contribute to the 'disorienting moments' ${ }^{28}$ which are a part of the clinical experience, this research has revealed the necessity to actively warn students that they may feel certain negative emotions during the reflective writing process itself. As part of the introductory sessions on reflective writing, it is considered necessary to advise students that feelings of awkwardness, discomfort, uncertainty, even a sense of being overwhelmed are all to be expected and are a 'normal' part of the reflection process. Students should be advised that they may find reflective writing to be annoying, tedious or challenging and that it will be timeconsuming. They may find it difficult and they may not enjoy it to start with. However, students should also be introduced to the idea that without these shifts in

\footnotetext{
${ }^{28}$ Quigley, above, n 22 and Spencer, above n 1, 193.
} 
comfort, students are unlikely to reach the requisite level of critical reflection that is the hallmark of good reflective writing.

Another important factor in overcoming negative sentiments is the necessity to suggest to students that an ability to reflect develops one's capacity to make moral judgments and to exercise ethically appropriate behaviour. In analysing some of the student comments that express negativity towards reflective writing, it has become clear that this link needs to be made by encouraging active discussion about this in class. Care needs to be taken in 'selling' the concept of reflection to law students. The ability to reflect is recognised as an important aspect of professional work. ${ }^{29}$ Students need to be guided through the literature on this to demonstrate how reflective practice helps to develop critical thinking, self-awareness and analytical skills. ${ }^{30}$ In addition, it is important to provide evidence for students (through the literature) that self-awareness has been identified as a skill that lawyers need.

An equally important issue which is articulated in the questionnaire responses is the recognition that some students do not find reflective writing to be intellectually vigorous. Reflective writing tasks should deliberately and expressly require students to engage with the relevant literature. Since commencing this research, I have started to include literature for students to read, discuss and present to the rest of the class

\footnotetext{
${ }^{29}$ See especially Schon, D.A. (1983) The Reflective Practitioner: How Professionals Think in Action, USA: Basic Books and Schön, DA, (1995-96) 'Educating the Reflective Legal Practitioner', 2 Clinical Law Review, 231.

${ }^{30}$ See Holland, L, (2013) 'Student reflections on the value of a professionalism model, 11(1) Journal of Information, Communication and Ethics in Society, 19-30 for an overview of reflective learning based on constructivist learning ideals and a discussion of this issue in the context of computer science, especially at page 20 .
} 
(as a seminar presentation) about self-awareness and emotional intelligence. In a very short time, I have noticed a marked positive change in student attitudes in class towards these concepts. The list of literature that I currently provide to students is appended at Appendix 5.

Recommendation Number 1: Advise students at the start of the term that feelings of discomfort are not unusual during the reflective writing process. Encourage students to write about their level of discomfort, why they think they feel uncomfortable, and whether the discomfort eases with time as they reflect and write more.

Recommendation Number 2: Introductory sessions about what is required in "good" reflective writing need to include room for discussion about the value of reflection and of reflective writing.

Recommendation Number 3: Assessment tasks should allow for rigorous discussion of the articles on the reading list. For example, students could be given specific questions based on a series of themes and asked to discuss and debate their answers using examples from their placements. For example: What is meant by client-centred practice? Do you agree that client-centred practice should be used in any kind of lawyer/client interaction? Use references from articles and examples from your own placement to support your answer. 


\section{Reinforce the positives}

Part II also highlighted that while many students raised negative issues, the research provides evidence that the conclusive response from students about reflective writing is that the majority of them found the positive aspects of the reflective writing tasks to outweigh any negative feelings they had. It is therefore considered important to advise students, as part of the introductory phase, that any negative attitudes they have may well be overtaken with positive responses by the end of the course. It is important to advise students that the reflective writing process evolves on a continuum that may vary in intensity of positive and negative sentiments towards actually doing the reflective writing. Just as the pedagogy that I have employed involves a gradual introduction to the skills inherent in the act of reflection, ${ }^{31}$ the development of those skills by students will involve a gradual understanding of how the process of reflection makes them feel. As the research shows, students themselves develop an appreciation of their own heightened selfawareness, a critical component of emotional intelligence. ${ }^{32}$ Personal awareness has been noted to be an important attribute of law graduates. ${ }^{33}$

Recommendation Number 4: When teaching students about the skills inherent in the act of reflection, advise them that whilst they may at times find

\footnotetext{
31 See Spencer, above n 1, 196.

32 James C, 'Seeing Things As We Are. Emotional Intelligence and Clinical Legal Education,' (2005) 8 International Journal of Clinical Legal Education 123, 138, discussed in Spencer, above, n 13.

${ }_{33}$ Boag A, Poole M, Shannon L, Patz C and Cadman F, (2010) Breaking the Frozen Sea: The case for reforming legal education at the Australian National University, ANU Law School Reform, 5, available at $<$ www.lawschoolreform.com>
} 
the reflective process difficult, the overall experience is designed to be a positive one.

\section{Degrees of difficulty}

There is no one particular aspect of reflective writing that students find difficult.

Different students find different aspects and stages of the reflective process to be difficult or challenging. The analysis of responses to question 2 (see Part II(2) above) shows the variety of issues which students perceive as 'difficult'. Some of these can be addressed in a practical way. For example, 'needs good memory or good record of event' can be addressed by recommending that students keep daily notes of each day of clinical placement which can be used an aide memoire when later writing a critical and dialogic reflection. Whilst this might appear to be an obvious solution, some students need to be given this suggestion.

Students have identified a number of difficulties that they experience in reflective writing. I now include a list of 'potential difficulties' that students may face as part of their assessment instructions. We also discuss these in workshops. In addition, time in class is now devoted to a discussion about these difficulties and strategies for overcoming them. For example, students are provided with the list of potential difficulties and then asked to comment on one or two of them (see Appendix 3).

A common theme in the list of 'difficulties' is that students find it hard to express their feelings and to evaluate themselves. The research did not probe what might 
have made this easier, nor why they find this difficult, although there are a number of speculatory theories that could be advanced. One is that law students are often 'A type' perfectionist, competitive personalities who are reluctant to reveal any kind of 'weakness'. An analysis of personal feelings, including doubts, hopes and fears may be a confronting task that the competitive law student may be reluctant to undertake. The issue of trust between student and lecturer/clinical supervisor becomes very important here. Students must be confident that their reflections remain confidential between them and whoever is reading or marking them. If confidences are to be shared with the class, this must be carefully negotiated. This is where the issue of trust between class members also becomes relevant. The pedagogy of reflective writing must include the development and maintenance of trust, not only between teacher and student but also within student peer groups. ${ }^{34}$ This is a phenomenon that in my experience usually occurs naturally across a period of time.

Recommendation Number 6: Students must be specifically told that their written reflections will be confidential, unless negotiated otherwise.

Recommendation Number 7: Open negotiation of the oral 'sharing' of experiences must occur in class with consensus as to how that will occur. For example, students might be encouraged to agree that they will not interrupt each other, not criticise, only offer constructive criticism, but be open to new

\footnotetext{
${ }^{34}$ See Spencer, above, n 1, 196 for a discussion on development of trust across the term.
} 
ideas. It is useful to facilitate such a discussion in the first class in order to reach consensus on how discussions of personal experiences will occur within the group.

Recommendation Number 8: Clinical teachers could present students with 'expectation of difficulty' as part of their instructions for reflective writing assignments, and discuss these potential difficulties in class. This will not only alleviate student anxiety ('Am I the only one who feels this way?) but it will also enable students to discuss their own experiences of reflective writing with a view to developing strategies for overcoming such difficulties.

\section{Subjects for reflection}

Not all students feel troubled or surprised by the clinical or placement experience. While some students may be anxious or nervous, many students are confident, happy and enjoy every moment of the placement. They do not have negative feelings to talk about. For example:

It's difficult to just be at placement and take it all in when you have to worry about finding something to worry about.

Some students expressed concern that that they had nothing to write about. One student made the comment:

I wished my placement was a little more law focussed $\mathcal{E}$ interactive so I could get the full benefits of reflective writing. 
Reflection need not be about something that is a source of concern. The 'disorienting' moment is only one prompt for reflection. It is important that students recognise that writing about experiences that they find positive are just as valid as writing about matters of concern or anxiety. Again, prompts are still useful in order to deepen the reflection, such as: 'What was the best thing about today?' 'Is there anything you could do in the future to improve this performance?' 'What advice would you give to a future student about developing confidence?' 'Do you want to work in this sort of environment? Why or why not?' 'What aspects of your supervisor's personality do you admire?' 'Why do you think the interview went so well?' 'What did you do to contribute to this being a positive experience?'

Recommendation number 9: Clinical teachers should use prompts to encourage students to reflect on positive experiences. Careful prompts need to be given to students who may feel that their placement does not provide enough opportunity for reflection.

\section{Mental health issues}

As a consequence of conducting this research, I have contemplated whether the reflective journal might be a tool of empowerment for students that could prevent 'mental health issues from consuming their life in law school'. ${ }^{35}$ The setting of personal goals and then the monitoring of those goals across a term can be very

\footnotetext{
${ }^{35}$ Gibson, Ben, 'How Law Students Can Cope: A Student's View', (2010-2011) 60 Journal of Legal Education 140.
} 
empowering for students. To be able to say, 'I achieved that' can be a step towards higher self-esteem and greater confidence. Students have a range of goals; it is considered important to always tell students that their goal will not be the same as the person sitting next to them, that they do not need to divulge their goals with the class and that their goals may change across a period of time. But whatever the goal is, it is important to work out a strategy for achievement. Some student goals are very practical: write better letters, learn how to draft a pleading, be better organised, update knowledge about a particular area of law. Others are more personal: overcome shyness around other work colleagues, overcome the fear of knocking on a supervisor's door or learn to ask for feedback. And others are quite specific: learn not to be defensive about negative feedback, think about the perspectives of others. Being forced to write about their goals through a reflective journal provides students with 'meaningful opportunities to reflect on their reasons for attending law school.' ${ }^{36}$ This has recently been found to be an important aspect of the law student experience. ${ }^{37}$ This desire by law students to be given opportunities to reflect on their reasons for studying law demonstrates that reflection goes beyond clinical legal education, and is important to all aspects of legal education. Gray points out that '[o]f great significance...is...the need for dialogue' between students and staff. ${ }^{38}$ Reflective report writing can provide that sort of dialogue which can be critical for

\footnotetext{
${ }^{36}$ Boag et al, above n33.

${ }^{37}$ Gray, J. (2012) 'Thawing Out the Law School: Why we need legal education theory', 37(3) Alt Law Journal 171.

38 Above, 173.
} 
students with a mental illness. Although this was not canvassed in my formal research, my experience has taught me that the reflective writing process has been extremely beneficial for some students who suffer from depression or anxiety, because it enables them to articulate their concerns and formulate strategies for addressing them, especially if sensitive and constructive feedback is provided.

Recommendation number 10: Clinical teachers need to be mindful of the diversity amongst students and tailor feedback to journal entries sensitively and compassionately.

\section{Balancing professional distance with reflection-in-action}

A number of students in the Focus Group and others who responded to the Questionnaire appear to find a lack of congruency between reflection and professional detachment. I am of the view that the two concepts are not mutually exclusive but that they need to be discussed with students. Students are coming through Law School with the idea that they have to 'blank ourselves out from having any emotional connection to anything' and that they have to 'turn themselves to stone' in order to 'think like a lawyer'. I find this alarming. After only a few years in Law School, students are feeling that they must not allow themselves to feel anything and that professionalism is dependent upon the necessity to stifle their own emotions. One can only hazard a guess in relation to the effect that this must have on students' emotional well-being and mental health but it can only be deleterious. It appears that class discussions about these issues are critical. I cover 
issues such as emotional intelligence, self-awareness, professionalism and clientcentred-practice but it appears that there is a lack of linkage between these topics. What is required is a deliberate and articulated link between each of these concepts.

Recommendation Number 11: Clinical teachers should articulate their own ideas about emotional intelligence and client-centred practice whilst making it clear that not all lawyers will agree on these issues.

\section{Re-badging 'reflection'}

A number of students expressed disdain, wariness and even contempt for the idea of reflection. A number of students when using the word 'reflection' in the Focus Group, used a tone of mock-seriousness combined with rolled eyes or a tone of sarcasm, hinting that 'reflection' is not something that serious lawyers do. However, the same students described the need for self-improvement and 'looking back' on what they had done. They also appeared to have no difficulty with using examples from their own experiences to explain their understanding of concepts raised in articles provided in their reading lists. A major negative factor appears to be the word 'reflection' itself, which seems to invoke discomfort. On the other hand, students say that would be happy to complete a 'project', to 'give them (the markers) what they want' and to 'reflect just after an interview'. It is perhaps the over-use of the word 'reflection' that is resisted. I am considering re-badging the concept of reflection in order to convey more meaning of what is required. For examples, students might be asked to write an 'interview analysis' or an 'article analysis', using 
examples from their own experiences to illustrate their understanding of the article(s). The term 'reflection' is viewed by students as heavily bound up with their emotional reactions to incidents and experiences. This is interesting in itself as this demonstrates a level of reflection that is purely egocentric rather than dialogical. However, this demonstrates a need for the Clinical teacher to provide convincing explanations of the benefits of dialogical reflection, as well as the development of emotional intelligence as a critical skill for lawyers.

'Recommendation' Number 12: This final idea is a suggestion rather than a recommendation, hence the quotation marks. Having not yet tried this myself, I am not in a position to recommend it. However, clinical teachers, might consider re-badging or re-labelling 'reflection' and 'reflective writing' by using descriptors which may appeal to students who prefer terminology which appears more scientific, such as 'Placement Analysis' or 'Clinical Retrospective', whilst still requiring students to engage in critical dialogic reflection as an essential component of such an 'analysis'.

\section{PART V: CONCLUSION}

This article provides an analysis of the results of formal research that was conducted into student perceptions of reflective writing in the clinical legal education context. The research was designed to investigate whether students perceived any benefit 
from reflective writing and what difficulties they actually encountered in writing in a way that is particularly different to other forms of academic assessment.

The objective of this research was to ascertain whether student perceptions of reflective writing match faculty perceptions of the benefits of reflective writing in clinical legal education. Qualitative research has revealed that perceptions differ amongst the student cohort and that not all students perceive a benefit from reflective writing in the clinical legal education context. However, the majority of students surveyed for this research indicated an appreciation of reflective writing as an enhancement to a clinical placement. Their responses have generated a series of recommendations that clinical legal educators might consider in their own pedagogical practices.

The first aim of this research was to ascertain the perceived benefits of reflective writing from a student perspective. The research has revealed that students perceive a variety of benefits, most particularly the development of critical thinking skills and as a tool for personal and professional development. The second aim of the research was to ascertain the sources of student anxiety in relation to reflective writing. These were revealed to be varied and numerous, and an important recommendation made in response to these concerns is to articulate their potential in advance to students and offer strategies for students to deal with these concerns. The third and final aim of the research was to develop an improved pedagogy of reflective writing in the clinical legal education context. The recommendations set out in Part IV offer several 
suggestions and recommendations as to how this might be achieved. These recommendations are relevant not only in law schools, but in any discipline where reflective writing is embedded within the curriculum. I sincerely thank the two anonymous reviewers who reviewed this article prior to publication. Their suggestions for this article, and in relation to potential areas for future research, were very helpful.

This research has deliberately focussed on reflective writing rather than reflective practice. It has highlighted student perceptions of difficulties associated with the practical reality of exercising reflective writing skills. Yet to be explored are the other potential types of reflective practice that could be employed in addition to (or alternative to) writing. Other types of reflective expression may well be possible in the clinical legal education context, such as mind maps, drawing, painting or film production. I have never asked students to produce forms of reflective expression other than prose writing. Perhaps this is an area to be further investigated. The possibilities are intriguing and exciting. Like my earlier article, this one has been written with a view to sharing my experiences so that other teachers of similar courses might benefit from my research and my conclusions and recommendations. 


\section{Appendix 1}

\section{Student Perceptions of the Role of Reflection in Clinical Legal Education}

\section{Participant Information Sheet}

This information sheet is for you to keep.

I am the Director of Professional Programs at the School of Law at the University of South Australia and I am gathering information for a research project about reflective writing. I would like to document my research with a view to publishing a peer reviewed article about my findings.

I invite you to participate in this research study. Participation is voluntary.

The aim/purpose of the research

The aim of the research is:

1) to investigate best practice for teaching reflection and reflective writing in a clinical legal education course, and

2) To investigate law students' perceptions of reflective writing.

What does the research involve?

I will ask you to complete a questionnaire. If you are interested, you are also invited to participate in a focus group to discuss reflective writing in more detail.

\section{Can I withdraw from the research?}

Participating in this research is voluntary and you are under no obligation to consent to participation. You may choose not to answer any of the questions.

\section{Confidentiality}

All questionnaires are anonymous and cannot be identified. If you participate in the focus group, your responses will be recorded and then transcribed but they will be de-identified. You will not be identifiable from the transcript. Given the nature of focus groups, confidentiality of focus group discussions and participation cannot be guaranteed. All information collected as part of the study will be retained in paper format (questionnaires) and on the UniSA computer system for ten years in a locked filing cabinet in my office at the School of Law at the City West campus of the University of South Australia. Only Rachel Spencer will have access to the data.

All records containing personal information will remain confidential and no information which could lead to identification of any individual will be released.

\section{Results}

If you would like a copy, I will provide you with a copy of my research findings in due course.

\section{Ethics Approval}

This project has been approved by the University of South Australia's Human Research Ethics Committee. If you have any ethical concerns about the project or questions about your rights as a participant, please contact the Executive Officer of this committee on telephone number+6188302 3118, email xxxx@unisa.edu.au

\begin{tabular}{|l|l|}
\hline $\begin{array}{l}\text { If you would like to contact the researchers about any aspect } \\
\text { of this study, please contact the Chief Investigator: }\end{array}$ & $\begin{array}{l}\text { If you have any questions or concerns about the manner in } \\
\text { which this research is being conducted, please contact: }\end{array}$ \\
\hline $\begin{array}{l}\text { Rachel Spencer } \\
\text { rachel.spencer@unisa.edu.au }\end{array}$ & $\begin{array}{l}\text { The Executive Officer } \\
\text { Telephone + } 61883023118 \\
\text { Email xxxx@unisa.edu.au }\end{array}$ \\
\hline
\end{tabular}

Rachel Spencer

Director of Professional Programs, School of Law 


\section{Appendix 2}

\section{FOCUS GROUP CONSENT FORM}

Project Title Student perceptions of the role of reflection in Clinical Legal Education

Researcher's name \& contact details: Rachel Spencer

Telephone: 8302 7946;

Email: rachel.spencer@unisa.edu.au.

- I have read the Participant Information Sheet, and the nature and the purpose of the research project has been explained to me. I understand and agree to take part.

- I understand that I may not directly benefit from taking part in the project.

- I understand that I can withdraw from the study at any stage and that this will not affect my status now or in the future.

- I confirm that I am over 18 years of age.

- I understand that I will be audio-taped during the focus group discussion

- I understand that the digital recording will be saved onto a USB and stored in Rachel Spencer's office (Room LB2-02B) in the Law School. The recording may be given to a person employed by a transcription service in order to transcribe the recording. In the event that the recording is transcribed, the transcription will be saved in digital format on a USB in Rachel Spencer's office (Room LB2-02B) in the Law School and a hard copy will also be kept in the same office. Apart from a person transcribing the recording, only Rachel Spencer will have access to the data.

- I understand that any data that the researcher extracts from the focus group discussions for use in reports or published findings will not contain names, but that my university may be identified.

- I agree to maintain confidentiality of the focus group discussions and preserve the identity of focus group participation.

\section{Name of participant}

\section{Signed}

\section{Dated}

I have explained the study to subject and consider that he/she understands what is involved.

\section{Researcher's signature and date}

This project has been approved by the University of South Australia's Human Research Ethics Committee. If you have any ethical concerns about the project or questions about your rights as a participant please contact the Executive Officer of this Committee, Tel: +61 88302 3118; Email: xxx@unisa.edu.au. 


\section{Appendix 3}

Class discussion question

Students have identified a number of difficulties that they experience in reflective writing, including:

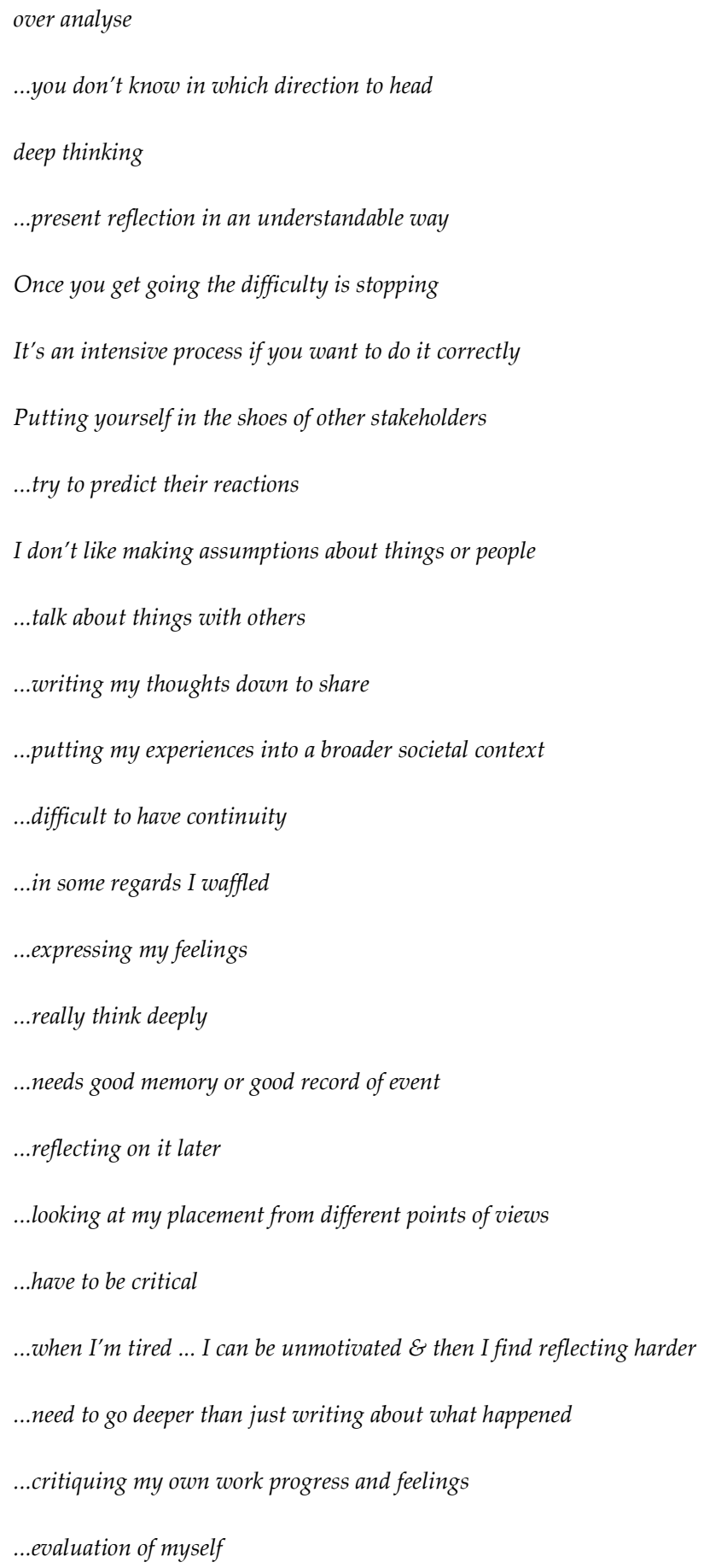

Choose one of these issues and be prepared to discuss the following in class:

- Identify an issue which is causing difficulty for you in your reflective writing.

- Consider and articulate what exactly is the real difficulty for you.

- Identify some strategies for overcoming this difficulty.

- Ask questions about the guidance you need to overcome this difficulty. 


\section{Appendix 4}

\section{Instructions for Students}

\section{Reflective Portfolio}

Your portfolio will consist of your revised and EDITED reflective journal entries as well as evidence that you have read widely on the topic you are covering. You should refer to articles and texts that are on the reading list and on the eReader. You are expected to engage in an intellectually reflective analysis of what these writers have said about certain topics. The portfolio may also contain newspaper cuttings, tables, graphs, cartoons, quotes, notes about films and television shows, descriptions of conversations, and anything that relates to your placement experience or topics covered in class. It will be a bit like a scholarly scrap book. All work of which you are not the author MUST BE properly attributed in footnotes and a bibliography.

The portfolio is not intended to consist of anecdotal recitation of activities. It is intended that the portfolio consist of students' observations and insights into their experiences on placement in the context of the specific topics that we cover in classes. In particular, the portfolio must show your development as a reflective learner. You are expected to select and describe experiences, analyse what happened, why it happened, what you learned from it, and how you would approach it next time. Honest and constructive analysis of one's own and others' performance, and the ability to take control of your own professional development is an integrally important part of the reflective learning process of any professional, and should be discussed in the portfolio. Your reflections must be critical reflections, not merely descriptive.

The portfolio must contain:

1) Two of the following written items:

1.1 A reflective analysis of an ethical issue that arose within your placement, including an analysis of relevant articles and texts.

1.2 A reflective analysis of an access to justice issue that arose within your placement, including an analysis of relevant articles and texts.

1.3 A reflective analysis of a law reform issue that arose within your placement, including an analysis of relevant articles and texts.

1.4 A reflective analysis of a client-centred practice issue that arose within your placement, including an analysis of relevant articles and texts.

1.5 A reflective analysis of a client interview, including an analysis of relevant articles and texts.

1.6 A reflective analysis of your view of the role of lawyers in society in the context of your placement experience(s), including an analysis of relevant articles and texts.

and

2) Two of the following written items:

2.1 A reflective analysis of your preparation for the Placement. This should include an analysis of your motivation (identifying what you wanted to achieve), your intentionality (planning your learning), your leaning objectives, self-awareness (identifying strengths and limitations) and your adaptability (preparing for the uncertainty of the workplace) and a critical reflection on the adequacy of your preparation.

2.2 A reflective analysis of your personal goals for the placement and whether or not you have achieved those goals or perhaps changed the goals as the term progressed. This analysis should include reflection on your own learning, your performance in the placement and your achievements, as well as plans for personal, educational and career development. 
2.3 A reflective analysis of an incident during your placement which involved you considering your personality type and your learning style compared with the personality of someone else at the placement office.

Each item must be clearly identified under one of the above headings. Each item may contain information or reflections from more than one day, especially if the incident took place over several days, or you want to talk about a series of events.

You are also expected to integrate the material discussed in seminars with your reflections about your placement experiences. Even though this is quite a personal piece of work you are still expected to write formally and to use proper footnotes and cite all articles correctly. Remember that you will need to edit your work stringently. The writing is the first part of the job. Editing it properly will take longer than the actual writing. The portfolio will be assessed according to the following criteria:

1) Ability to identify and focus on salient issues from each situation;

2) Analysis of your own perspective and the perspectives of others;

3) Use of a variety of resources in order to analyse the situation and to cite them appropriately;

4) Ability to place the event(s) or situation(s) in the context of broader social, political and professional perspectives and to analyse how these perspectives influence the event or situation;

5) Identification of the learning that you have achieved and your learning needs;

6) Ability to write clearly and coherently.

\section{Appendix 5 List of Literature for Students}

Egan, G. (2002) Sharing empathic highlights: communicating and checking understanding, The Skilled Helper: a problem-management and opportunity development approach to helping, Pacific Grove, California: Brooks/Cole Publishing Co., Chapter 6, pp 93-116.

Ellmann, S. (1987) Lawyers and Clients, 34 UCLA Law Review 717

Binder, D. and Price, S (1977) Extracts from 'Legal Interviewing and Counselling: a client-centred approach', St. Paul, Minn.: West Pub. Co.

Wasserstrom, R. (1975) Lawyers as Professionals: Some Moral Issues, 5 Human Rights 1

Hyams, R, Campbell, S, Evans, A. (2014) 'Interviewing', Practical Legal Skills $4^{\text {th }}$ Ed., South Melbourne, Victoria: Oxford University Press.

Allegretti, J. (1993) 'Shooting elephants, serving clients: an essay on George Orwell and the lawyerclient relationship', 27 Creighton Law Review 1.

Ipp, D.A. (1995) Judicial Intervention in the Trial Process, 69 (5) Australian Law Journal 365

Genn, H. (1993) Tribunals and Informal Justice, 56(3) The Modern Law Review 393

Luban, D. (1988) The Case of the Wicked Uncle, Lawyers and Justice: An Ethical Study, Princeton N.J.: Princeton University Press, 3-10

Nicholson, R. (2005) Can courts cope with self-represented litigants? 8 (2) Flinders Journal of Law Reform 139

Rhode, D. (2004) Access to Justice: connecting principles to practice, 17 Georgetown Journal of Legal Ethics 369

Wertheimer, A. (1998) 'The equalisation of legal resources', 17 (4) Philosophy and Public Affairs, 303. 
Sarre, R. and Vernon A. (2013) 'Access to safe justice in Australian Courts: some reflections upon intelligence, design and process', 2 (2) International Journal for Crime, Justice and Social Democracy.

Thompson, E. (2011) 'Does the open justice principle require cameras to be permitted in the courtroom and the broadcasting of legal proceedings?' 3 (2) Journal of Media Law 211.

Burgess, S. (2010) 'Aboriginals in the Courtroom: recognising cultural differences', Bulletin (Law Society of South Australia), 12-14.

Minow, M. (1991) 'Breaking the law: lawyers and clients in struggles for social change', 52 U. Pitt. Law Review 723.

Young, I.M. (1991) 'Professional ethics and social change: a response to Minow', 52 U. Pitt. Law Review 859.

Luban, D. (1991) 'Conscientious lawyers for conscientious lawbreakers', 52 U. Pitt. Law Review 793.

Balos, B. (1997) 'The bounds of professionalism: challenging our students, challenging ourselves', 4 Clinical Law Review 129.

Ogilvy, J.P. (1997) 'The use of journals in legal education: a tool for reflection', 3 Clinical Law Review 55.

Aaronson, M.N. (2002) 'Thinking like a fox: four overlapping domains of good lawyering', 9 Clinical L. Review 1.

Silver, M. (2006) 'The professional responsibility of lawyers: emotional competence, multiculturalism and ethics', 13 Journal of Law and Medicine 431.

Spigelman, J. (2011) 'Truth and the Law', 85 Australian Law Journal 746.

Margulies, P. (1990) "“Who are you to tell me that?" Attorney-Client deliberation regarding non-legal issues and the interests of non-clients', 68 N.C. L. Rev. 213.

Aiken, J.H. (1997) Striving to teach justice, fairness and morality', 4 Clinical Law Review 1.

James, C. (2011) 'Law student well-being: benefits of promoting psychological literacy and selfawareness using mindfulness, strengths theory and emotional intelligence', 21 (1/2) Legal Education Review 217.

Berger, L. (1999) 'Applying New Rhetoric to legal discourse: the ebb and flow of reader and writer, text and context', 49 Journal of Legal Education, 155.

Giddings, J. (2013) 'Promoting justice through clinical legal education' (e-book) Melbourne: Justice Press.

Margulies, P. (1994) 'The mother with poor judgment and other tales of the unexpected: a civic republican view of difference and clinical legal education', 88 Northwestern University Law Review 695. 